\title{
Opinião
}

\section{ECOLOGIA: ASPECTOS LEGAIS E A NECESSIDADE DE UMA CONSCIÊNCIA AMBIENTAL}

Fernanda Fernandes de Sousa Lima (1)

Fábio Firmino de Araújo (2)

Atualmente, tem-se discutido muito a cerca de aspectos socioeconômicos, políticos, culturais, religiosos, como influenciadores do processo da vida humana.

Estudos tem demonstrado elevados índices de desenvolvimento humano em determinadas regiões da Europa, América do Norte, Oceania, enquanto que na América Latina, Ásia e África predominam baixos índices. No Brasil os melhores índices estão nos estados das regiões sul e sudeste e os mais baixos estão nas regiões nordeste e norte (SUAREZ, 2000).

Será que existe uma forma legal de minimizar essas diferenças? Neste sentido, o artigo $3^{\circ}$ da Lei $n^{\circ}: 6.938$ de 31 de agosto de 1981 nos informa sobre o conceito legal de meio ambiente: "O conjunto de condições, leis, influências e interações de ordem física, química e biológica, que permite, abriga e rege a vida em todas as suas formas" (MAGALHÃES, 1998).

As leis, tendem a criar uma expectativa social de ordem e organização, de interesse coletivo. Assim, o valor contido nas normas se expande para além do aspecto jurídico, com a finalidade de constituir uma consciência moral coletiva que proporcione a sociedade um bem maior que é o bem-estar de todos, o benefício da ordem coletiva. Esses com a finalidade de proporcionar a todos uma maior grau de satisfação.

O valor da norma não está na lei em si, muito menos na sua aplicabilidade do ponto de vista judicial, quando alguém é impelido por esta a fazer ou deixar de fazer alguma coisa. As leis e normas deveriam ir além da obediência ou não a algum interesse. E sim, implicar uma preocupação com os demais semelhantes. 
As leis, trariam realmente algum benefício social verdadeiro, se realmente nos sensibilizar a um ordenamento jurídico, porém consciente de nossas necessidades, disponibilidades e também de nossa interação uns com os outros. Esse valor ultrapassa os limites míopes do interesse individual de quem apenas pensa em suas possibilidades e em suas próprias virtudes, esquecendo-se (ou nunca lembrando) de que nenhum indivíduo é uma ilha e que todos dependem de todos.

O direito ambiental têm por finalidade a conservação não apenas de um patrimônio que é comum a todos, mas a conservação da própria existência da raça humana; ou seja, tratase de uma questão de sobrevivência em que todos são beneficiários ao mesmo tempo em que são responsáveis.

O final dos anos sessenta e início dos anos setenta surgiu um movimento que trouxe a tona discussões que até então encontravam-se restritas aos ambientes acadêmicos das grandes universidades do Estados Unidos da América e da Europa, onde cada vez mais os recursos naturais estavam e estão exaurindo o meio ambiente e tornando a cada momento mais difícil a sobrevivência humana.

Estas observações sobre a necessidade de conservação do meio ambiente foram suscitadas pelo químico e pesquisador inglês James Lovelock, cujas pesquisas pressupõem que a terra possua um mecanismo próprio de auto-regulação da composição da atmosfera terrestre.

Em 1979 James Lovelock publicou algumas de suas idéias no livro "Gaia: A New Look at Life on Earth" no qual postula a Hipótese Gaia. Esta hipótese afirma que as condições químicas e físicas da superfície da Terra, da atmosfera, e dos oceanos buscam ajustar-se a fim de criar as condições adequadas a presença de vida. Esta proposição vai de encontro ao pressuposto convencional de que a vida se adaptou as condições de vida planetárias existentes na Terra e, desde então, ambas evoluíram porcaminhos diferentes. Segundo o autor, a definiçãa de Gaia seria um ente complexo que inclui a biosfera terrestre, atmosfera, oceanos, e solo. Uma totalidade estabelecendo um mecanismo auto-regulador de sistemas cibernéticos com a finalidade de procurar um ambiente físico e químico ótimo para a vida no planeta (LOVELOCK,1991).

Neste caso o Planeta e seus componentes constitutivos poderiam ser visto como partes de uma entidade vivente única capaz de manter a composição da atmosfera da Terra adequada a suas necessidades gerais e dotada de faculdades e poderes maiores que a aquelas das suas partes constitutivas. Segundo esta proposição, a conservação da Terra depende a nossa permanência e perpetuação. 
$\mathrm{Na}$ mitologia, Gaia personifica a origem do mundo, a protetora da fecundidade e dos jovens, porém sujeita a necessidade de preservação do meio ambiente como motivo fundamental para a sobrevivência nossa e de nossos descendentes.

\section{A terra como direito de todos}

Partindo-se dessa premissa, há de se refletir a necessidade de uma regulação das formas de interações entre indivíduos e o meio ambiente com a finalidade única e exclusiva de estabelecer a conservação de uma em favor da preservação do outro. E nesta linha de raciocínio, lançamos mão do direito enquanto ciência reguladora das relações para, à partir de princípios e normas buscarmos a equalização desta problemática que, aparentemente parece sem solução, posto que extrair recursos do meio ambiente é a forma que se conhece de satisfazer as necessidades básicas para nossa própria sobrevivência.

Como as medidas reguladoras não têm se mostrado eficientes, a conservação do meio ambiente tornou-se, nos últimos tempos, uma questão primordial para que o homem possa pensar não apenas em sobrevivência, mas também em permanência e perpetuidade.

Assim, a destruição de florestas e matas e a extração descontrolada de recursos naturais, tornou-se alvo da atenção de todos os envolvidos, mais precisamente aqueles ligados às ciências e ao direito.

É preciso determinar até que ponto a coletividade está sendo atingida e em que magnitude, posto que pode estar se pondo em risco a própria humanidade. O Direito ambiental surge então, como pano de fundo e, ao mesmo tempo como elemento útil e necessário para a sobrevivência da raça humana.

Observe-se: O conjunto de leis atualmente em vigor sobre meio ambiente constitui um arcabouço regulamentar que atua como protetor, punindo eventuais danos ambientais, considerando-se aqueles danos cujos resultados verificar-se-ão danosos à uma coletividade.

O Direito ambiental possui um conjunto lógico de regulamentos que estabelece seus limites de diretrizes, como forma de integrar-lhe um conjunto normativo devidamente estruturado e racionalmente instruído, e cujas orientações vão representar os valores que deverão ser protegidos com vistas à preservação de um bem comum.

Um destes princípios - chamado de "princípio da precaução" - foi consagrado pela Declaração do Rio de Janeiro, e tem no seu enunciado $n^{\circ} .15$ a seguinte redação:

"Para proteger o meio ambiente, medidas de precaução devem ser largamente aplicadas pelos Estados, segundo suas capacidades. Em caso de 
risco de danos graves ou irreversíveis, a ausência de certeza científica absoluta não deve servir de pretexto para procrastinar a adoção de medidas efetivas visando prevenir a degradação do meio ambiente" (Declaração do Rio sobre Ambiente e Desenvolvimento de Junho de 1992).

Essa alegação possui um caráter muito mais mercantilista e utilitarista, posto que minimiza os efeitos do princípio adotado enquanto não tornada realidade a "certeza científica", protegendo muito mais os interesses econômicos de grandes grupos industriais e mercantis, do que a efetiva proteção ao indivíduo, que deveria ser o alvo direto da proteção estabelecida pelo direito ambiental.

Dessa forma, a alegação trata de um assunto discutível e repleto de considerações das mais diversas ordens, já que no direito enquanto ciência, o que interessa é a análise do pressuposto e não uma digressão, positiva ou negativa, sobre múltiplas possibilidades acerca do mesmo tema.

De qualquer maneira, o que não podemos acreditar é que apenas e tão somente um conjunto de leis e pressupostos de direito são suficientes para garantir e assegurar que as devastações ambientais, os acidentes danosos e demais eventos de caráter destrutivo não mais tornarão a ocorrer e ainda, que diversas e múltiplas populações espalhadas pelo nosso planeta possuam o necessário comprometimento com a sua efetiva consecução. Ou seja, uma imagem não nos diz nada se não trouxer consigo uma carga significativa de representatividade capaz de sensibilizar os indivíduos não apenas sobre a problemática envolvida, mas também e principalmente, sobre a importância de sua repercussão (positiva ou negativa), bem como seus efeitos reflexos sobre si próprio, seus ascendentes, descendentes e semelhantes, de modo que a consciência ecológica torne-se um fato imediato e plenamente assumido.

Portanto, estabelecer uma política de meio ambiente, a construção de um conjunto regulador das atividades econômicas auto-sustentáveis e a conseqüente aplicação de um sistema sancionador capaz e eficiente por si mesmo, não constituem o mínimo necessário para que se estabeleça uma consciência ecológica. Não se trata de declarar que a existência e adequação de um conjunto normativo não são necessárias ou indispensáveis para que a conservação ambiental torne-se uma realidade cada vez mais próxima a todos, mas, de refletir a preservação, conservação e manutenção do meio ambiente, como única forma de saber-se que, aquilo que nos serve hoje deverá também servir aos nossos filhos e netos assim como também aos nossos semelhantes. 


\section{O aquecimento global}

O chamado efeito estufa, fenômeno pelo qual alguns gases como o vapor d'água, dióxido de carbono (CO2) e metano (CH4) são capazes de reter o calor do Sol na atmosfera, tem ocupad os noticiários de muitos jornais atualmente. Sem esses gases, a radiação solar se dissiparia no espaço e nosso planeta seria cerca de $30^{\circ} \mathrm{C}$ mais frio. Com eles, parte do calor do sol refletido na superfície terrestre fica "preso" na atmosfera, mantendo a temperatura necessária para a existência de grande parte da vida no planeta. $\mathrm{O}$ fenômeno é semelhante ao ocorrido em uma estufa, que mantém o calor preso dentro de um ambiente específico. Daí o nome de efeito estufa (KIRCHHOFF, 1992).

Há claros sinais de que atividades humanas estão aumentando a emissão dos gases que causam o efeito estufa. Com isso, a Terra está ficando mais quente. As últimas décadas do século XX tiveram as mais altas temperaturas médias. Nos últimos 50 anos, os Alpes na Europa perderam $50 \%$ de sua cobertura de gelo. Dados sobre amostras profundas de gelo sugerem que vivemos o século mais quente dos últimos 600 anos. Hoje, a temperatura média do planeta está $4^{\circ} \mathrm{C}$ acima do que era na última idade do gelo, uns 13 mil anos atrás. (GREENPEACE, 1992)

Muitas foram as modificações climáticas que os cientistas afirmam serem resultado da intensificação do efeito estufa. Somos mais de 6 bilhões de seres humanos em atividade na terra. Parte da quantidade de $\mathrm{CO}_{2}$ emitida na atmosfera é absorvida pelas florestas do planeta que, dessa forma, ajudam a estabilizar o clima mundial. Mas, quando florestas são queimadas, a substância retida volta à atmosfera (WHITE et al, 2000) .

Os países desenvolvidos queimam muito mais combustíveis fósseis do que os países em desenvolvimento e mais de $90 \%$ do $\mathrm{CO} 2$ produzido por atividades humanas provém da Europa e da América do Norte (GREENPEACE, 1992).

Segundo cientistas, a tendência da temperatura média da Terra é aumentar ainda mais. À medida em que o planeta esquenta, a cobertura de gelo dos Pólos Sul e Norte derrete. Quando o calor do sol atinge essas regiões, o gelo reflete a radiação de volta para o espaço. Se a cobertura de gelo derreter, menos calor será refletido. É provável que isso torne a Terra ainda mais quente.

Em efeito cascata, à medida em que o gelo das calotas polares derrete, eleva-se o nível do mar, provocando outro tipo de dificuldade: inundação ou submersão de terras mais baixas no Oceano Pacífico, avalanches, erosão dos solos e mudanças dramáticas no fluxo dos rios, grandes variações no ritmo de chuvas, furacões e tormentas, em alguns pontos e secas em 
outros, crescimento dos desertos nas regiões semi-áridas, dentre outras (GREENPEACE, 1992).

Um dos grandes perigos do aquecimento é o provável impacto na baixa produção de alimentos, redução ou extinção de muitas espécies de animais que não seriam capazes de se adaptar às novas condições ambientais. Essas são situações que afetariam sensivelmente o equilíbrio de diversos ecossistemas. Outro problema igualmente importante seria a ocorrência de epidemias de doenças transmitidas por insetos que o calor aumenta as chances de sobrevivência dos germes, bactérias, esporos e outros organismos prejudiciais à saúde humana (VIEIRA, 2004)

Considerado dessa forma, o aquecimento global poderá ter efeitos destrutivos sobre a humanidade pois trata-se de um processo que tende a evoluir por si mesmo. Assim, nos perguntamos: qual a justificativa prática para um conjunto de normas jurídicas que, além de não serem eficazes o suficiente para deter a ação do homem sobre o planeta, parece sem significado para a maioria dos que dela se utilizam?; Como fornecer recursos emocionais capazes de formar uma “ consciência ecológica" capaz de impulsionar o homem a reagir com ações relacionadas a conservação dos nossos recursos naturais e à própria conservação da vida no planeta?; Será que não é nosso dever a construção de um mundo melhor?

Concluímos pois que, a construção de uma consciência em torno da importância da ecologia e do meio ambiente, não pode ser fruto da imposição de um conjunto de normas. A formação de uma consciência ecológica exige a participação ativa de cada um individualmente e do seu integral envolvimento com o problema. Além disso, é necessária uma constante preocupação com a busca de soluções que tenham por meta deter o avanço de um evento danoso para o meio ambiente e para os seres que hoje habitam o Planeta.

\section{Referências:}

DECLARAÇÃO do Rio sobre Ambiente e Desenvolvimento de 06/1992. Disponível em < http://www.cnrh-srh.gov.br/camaras/GRHT/itemizacao/rio92.htm >. Acesso em 24 de outubro de 2008.

GREENPEACE. Aquecimento global. O relatório do GREENPEACE. Ed. Fundação Getulio Vargas, Rio de Janeiro - RJ, 1992.

KIRCHHOFF, V. W. U. Queimada na Amazônia e o efeito estufa. Ed. Contexto, São Paulo, 1992. 
LOVERlocK, J. E. GAIA: The Practical Guide to Planetary Medicine. Gaia Books: London, 1991.

MAGAlhãeS, J.P. A Evolução do Direito Ambiental no Brasil. São Paulo: Oliveira Mendes, 1998.

WHITE, A.; CANNEL, M.G.R.; FRIEND, A.D. $\mathbf{C O}_{2}$ stabilization, climate change and the terrestrial carbon sink. Global Change Biology 6: 817-833. 2000.

SUAREZ, M.L.H. Política energética e desenvolvimento sustentável: taxa sobre o carbono para a mitigação de gases de efeito estufa no Brasil. Tese (Doutorado em Engenharia). Faculdade de Engenharia, Universidade Estadual de Campinas. Campinas. 2000.

VIEIRA, P.F. Gestão de recursos naturais renováveis e desenvolvimento: novos desafios para a pesquisa ambiental. São Paulo: Cortez, 2004.

Sobre os autores:

(1) Fernanda Fernandes de Sousa Lima é Bióloga pela universidade Regional do Cariri - URCA. E-mail: fernandafsl_msn@hotmail.com .

(2) Fábio Firmino de Araújo é graduado em Ciências Jurídicas e Mestre em Sociologia pela UFPB.

E-mail: fabiofir@terra.com.br 